Canadian Journal of Fisheries and Aquatic Sciences Journal canadien des sciences halieutiques et aquatiques

\title{
Predation by introduced fish can magnify the terrestrial arthropod subsidies in mountain lakes
}

\begin{tabular}{|c|c|}
\hline Journal: & Canadian Journal of Fisheries and Aquatic Sciences \\
\hline Manuscript ID & cjfas-2017-0121.R2 \\
\hline Manuscript Type: & Article \\
\hline Date Submitted by the Author: & 02-Nov-2017 \\
\hline Complete List of Authors: & $\begin{array}{l}\text { Rolla, Matteo; Swansea University, Department of BioSciences } \\
\text { Biffoni, Geordie; University of Genova } \\
\text { Brighenti, Stefano; University of Trento } \\
\text { Iacobuzio, Rocco; Università Statale di Milano, Dipartimento di Bioscienze } \\
\text { Liautaud, Kevin; Ente Parco Nazionale Gran Paradiso } \\
\text { Pasquaretta, Cristian; Toulouse University } \\
\text { Tiberti, Rocco; Universita degli Studi di Pavia, DSTA }\end{array}$ \\
\hline $\begin{array}{r}\text { Is the invited manuscript for } \\
\text { consideration in a Special } \\
\text { Issue? : }\end{array}$ & N/A \\
\hline Keyword: & $\begin{array}{l}\text { CONSERVATION < General, ALPINE < Environment/Habitat, LAKES < } \\
\text { Environment/Habitat, AIR-WATER INTERACTION < General }\end{array}$ \\
\hline
\end{tabular}

\section{SCHOLARONE}

Manuscripts 
1 Title page:

2 Predation by introduced fish can magnify the terrestrial arthropod subsidies in mountain

3 lakes

4

5 Matteo Rolla ${ }^{1,2}$, Geordie Biffoni ${ }^{3}$, Stefano Brighenti ${ }^{2,4,5}$, Rocco Iacobuzio ${ }^{2,6}$, Kevin Liautaud ${ }^{2}$,

6 Cristian Pasquaretta ${ }^{7}$, Rocco Tiberti $^{2,8, *}$

7

$8 \quad{ }^{1}$ Department of BioSciences, Swansea University, Singleton Park, SA2 8PP, Swansea, UK

$9{ }^{2}$ Alpine Wildlife Research Centre, Parco Nazionale Gran Paradiso, Degioz 11, 11010

10 Valsavarenche, Aosta, Italy

$11{ }^{3}$ DISTAV, Dipartimento di Scienze della Terra, dell'Ambiente e della Vita, Università di

12 Genova, Corso Europa 26, 16132 Genova, Italy

$13{ }^{4}$ Dipartimento di Ingegneria Civile, Ambientale e Meccanica, Università degli studi di

14 Trento, via Mesiano 77, 38123 Trento, Italy

$15{ }^{5}$ Sustainable Ecosystems and Bioresources Department, Fondazione E. Mach, IASMA

16 Research and Innovation Centre, Via E. Mach 1, 38010 San Michele all'Adige, Trento, Italy

$17{ }^{6}$ DBS, Dipartimento di Bioscienze, Università degli Studi di Milano, Via Celoria 26, 20133

18 Milano, Italy

$19{ }^{7}$ Centre de Recherches sur la Cognision Animale (CRCA), Centre de Biologie Intégrative

20 (CBI), Université de Toulouse, CNRS, UPS, Bât 4R3, 118 Route de Narbonne, 31062 Cedex

21 9, Toulouse, France

$22{ }^{8}$ DSTA, Dipartimento di Scienze della Terra e dell'Ambiente, Università di Pavia, Via 23 Ferrata 9, 27100 Pavia, Italy 
24 * Correspondence: Rocco Tiberti, DSTA, Dipartimento di Scienze della Terra e

25 dell'Ambiente, Università di Pavia, Via Ferrata 9, 27100 Pavia, Italy. Mobile: 0039340

264717352 e-mail: rocco.tiberti@gmail.com

27

28 Abstract.

29 A portion of the terrestrial subsidies to lentic habitats consists of arthropods. In high

30 mountain, originally fishless lakes, terrestrial arthropods are an important seasonal food

31 resource for introduced fish. Here we investigate how brook trout Salvelinus fontinalis can

32 alter the input of terrestrial arthropods in ten high mountain lakes contrasting for their

33 stocking history (with and without fish, or manipulated for fish eradication). We used a food

34 consumption model to calculate the minimum and maximum number/biomass of arthropods

35 consumed by fish and we found that they can exceed several folds the number/biomass of

36 arthropods sinking into the lakes, at least under the metabolic rates expected for fish for most

37 of the summer. We interpret this result as an indirect indication that arthropods usually

38 cannot overcome the surface tension at the lake surface and that fish can work as a vector

39 across the water-air interface. We infer that pathways for dead and alive arthropods to leave

40 the lakes do exist and fish can transfer into the water column many arthropods whose fate

41 was leaving the lakes, which may have overlooked ecological and conservation implications.

43 Keywords. Brook trout, ecological linkages, Gran Paradiso National Park, LIFE+ Project

44 BIOAQUAE, fish eradication 


\section{Introduction}

46 Terrestrial subsidies to aquatic habitats include all nutrients of terrestrial origin which

47 are incorporated into the aquatic food web, becoming available in the form of

48 dissolved/particulate organic carbon and terrestrial prey (e.g. terrestrial organisms consumed

49 by aquatic predators) for aquatic biota (Vander Zanden and Gratton 2011). Land-to-lake

50 linkage pathways are largely governed by physical vectors such as gravity, run-off,

51 precipitation, wind. However, they may also be mediated by biotic vectors including

52 dispersal events of terrestrial prey organisms, which may fall into the water (Mehner et al.

53 2005; Bartels et al. 2012).

54 Terrestrial subsidies can fuel the metabolism of aquatic habitats to a variable extent,

55 with the impact on nutrient balance of lakes depending on a number of local factors (Vander

56 Zanden and Gratton 2011). In general, they represent a more significant fraction of the

57 nutrient balance in small oligotrophic lakes (Mehner et al. 2005; Vander Zanden and Gratton

58 2011), such as most small lakes of glacial origin. These are the most common type of lake

59 found globally, and are usually unproductive lakes located in polar and mountain regions.

60 They possess a net heterotrophic metabolism, meaning that bacterial respiration is greater

61 than primary production and that the local food webs rely on external/terrestrial nutrient

62 sources (del Giorgio et al 1997; Cole et al 2006).

63 Due to their biogeographic history and when downstream physical barriers are present

64 (i.e. cascades), mountain lakes are originally fishless. In recent decades, predatory fish (e.g.

65 Salmonidae and Cyprinidae minnows of the genus Phoxinus) have been introduced to many

66 formerly fishless lakes for recreational angling (Miró and Ventura 2013, 2015; Ventura et al.

67 2017). Fish introduction usually causes the loss of native species (amphibians,

68 macroinvertebrates and large zooplankton; Knapp et al. 2001; Tiberti et al. 2014a), and

69 results in other indirect ecological impacts (e.g. affecting the nutrient cycles and the trophic 
state of invaded ecosystems; Schindler et al. 2001; Eby et al. 2006). For example, by feeding on large planktonic herbivores fish can benefit pelagic primary production by decreasing grazing pressure. Besides, by feeding on aquatic and terrestrial prey and excreting wastes in the pelagic zone, fish transfer a small amount of nutrients to the water column of high altitude lakes (Schindler et al. 2001; Milardi et al. 2017) and other lentic habitats (Pace et al. 2004; Persson and Svensson 2006; Carpenter et al. 2011). Incidentally, fish introductions provide an interesting opportunity to compare stocked and natural fishless lakes. Since fish eradications are a realistic conservation measure in high altitude lakes (Knapp and Matthews 1998), they also provide the rare opportunity to manipulate the presence of introduced predators in the wild. These characteristics made high altitude lakes ideal model ecosystems to study the ecological role of introduced fish.

The role and the magnitude of arthropod input is an overlooked issue in lake ecology (Wurtsbaugh 2007; Piovia-scott et al., 2016), probably because terrestrial arthropods and arthropod fragments account for a small fraction of the total terrestrial subsidies and nutrient budget into lakes (Cole et al. 1990; Cole et al. 2006; Mehner et al. 2005; Wurtsbaugh 2007; but see Carlton and Goldman 1984; Nowlin et al. 2007 for massive arthropods fallouts and their ecological consequences). However, terrestrial arthropods represent a notable fraction of airborne inputs of organic matter (Vander Zanden and Gratton 2011), and a very important food resource during the ice-free season for introduced fish populations in small oligotrophic glacial lakes (e.g. Mehner et al. 2005; Milardi et al. 2015; Tiberti et al. 2016). Here terrestrial arthropods may have a stabilizing role in fish energetics and contribute to the maintenance of fish abundances (Piovia-Scott et al., 2016). Since these fish are introduced species, their impact on the reciprocal subsidies between lakes and surrounding terrestrial habitats is also a conservation issue needing to be thoroughly understood. 
94 In the present study, we take advantage of the features which make high altitude lakes 95 good model ecosystems and of a recently completed fish eradication campaign, with the aim 96 of understanding whether the terrestrial arthropod subsidy (arthropods input into the lakes) is 97 influenced by introduced fish. The present study was carried out in ten high altitude lakes 98 contrasting in stocking history: 3 naturally fishless lakes, 3 lakes with brook trout Salvelinus 99 fontinalis Mitchill 1814, and 4 lakes treated for brook trout eradication. We therefore 100 measured the number of sinking arthropods at different depths in the three lake categories to test our first study hypothesis: (H1) a proportion of terrestrial arthropods falling into the lakes, which would have formerly sunk to lake bottom, is diverted to fish. However, the number of sinking arthropods was so much lower than our naïve expectations, that our test of study hypothesis concerning the low number of sinking arthropods. We compared the number/biomass of sinking arthropods and the number/biomass of terrestrial arthropods consumed by the populations of brook trout (as an indirect, minimum estimate of the number of arthropods falling onto the lakes' surface), to indirectly test our second hypothesis: (H2) a proportion of the terrestrial arthropods falling onto the lake surface do not overcome the surface tension of the water, and fish predation works as a vector across the water-air interface, i.e. between the lake surface and the water column. The number/biomass of consumed arthropods in the lakes treated for fish eradication was estimated with a food consumption model. Both $\mathrm{H} 1$ and $\mathrm{H} 2$ predict that fish can divert (in the form of metabolic wastes, rich in nutrients) some terrestrial arthropods into the water column, changing their final (benthic habitats for H1) or temporary (lakes' surface for H2) destinations. H1 is verified if the proportion of sinking arthropods reaching the bottom is larger in fishless lakes than in the presence of introduced fish. $\mathrm{H} 2$ is verified if the number/biomass of terrestrial 
118 arthropods consumed by fish is larger than the number/biomass of terrestrial arthropods

119 sinking into the lakes.

120 We complemented the study with two field tests concerning the time of underwater

121 arthropod decomposition, and the relationship between number of sinking arthropods and

122 distance from the shoreline. These tests were performed to ensure that the used methods were

123 suitable to quantify the number of terrestrial arthropods sinking into lakes and to discuss

124 some overlooked aspects of the sampling design.

Methods

Study lakes

All the study lakes are included in the Gran Paradiso National Park (GPNP), a large protected area located between $45^{\circ} 25^{\prime}$ and $45^{\circ} 45^{\prime} \mathrm{N}$ and between $7^{\circ}$ and $7^{\circ} 30^{\prime} \mathrm{W}$ in the Western Italian Alps (Fig. 1). The GPNP shows a large altitudinal extension (between 800 and 4,061 m) and a typical alpine climate. Toponyms of the lakes will be replaced by abbreviations: Nivolet superiore-NIS; Trebecchi superiore-TRS; Losere-LOS; Leità-LEI; Rosset-ROS; Nivolet inferiore-NII; Leynir-LEY; Nero-NER; Djouan-DJO; Dres-DRE. The main geographical, morphological and chemical features of the study lakes are reported in Table 1. The lakes are natural (non-dammed) and they are all located above or at the local tree line with their watersheds belonging to the alpine and nival belts. Thermal stratification occurs only late in the summer in the deepest lakes and the ice-covered season lasts for 7-9 months per year (Tiberti et al. 2010). Based on nutrient content, the studied lakes are oligotrophic or ultraoligotrophic. The presence of brook trout dates back to the 1960s. 
143 Sampling and analytical methods

144

145

146

147

148

149

150

151

152

153

154

155

\section{Funnel traps for sinking arthropods}

To sample the sinking arthropods, we used submerged funnel-traps (inverted cones) constructed with a plastic net (1 mm mesh-size) with their mouth facing upwards (Fig. 2A), which are a variant of the sedimentation traps (Bloesch and Burns 1980), but suitable to retain only larger particles, i.e. arthropods.

\section{Proportion of sinking arthropods reaching the lake bottom}

We used a paired benthic and surface funnel trap design (Fig. 2B) to test whether fish presence affects the proportion of terrestrial arthropods reaching the bottom (H1). The surface trap should give an estimate of the number of sinking arthropods before being preyed upon by fish feeding above the bottom trap ( $\approx \approx 1.5 \mathrm{~m}$ section of water column). During the 2013 ice-free season, between June $25^{\text {th }}$ and September $7^{\text {th }}$, we repeated 2-3 sampling sessions in all the study lakes (obtaining 8-14 replicates of paired benthic and surface samples of terrestrial arthropods for each lake; Table 2). During each sampling session, four plots of traps were placed along the two-meter isobaths and left in the lakes for 4-12 days. Each plot consists of one pair of traps. One trap was placed approximately five $\mathrm{cm}$ below the water surface and the other was suspended above the lake bottom. There was approximately $1.5 \mathrm{~m}$ between the mouths of the two traps. Each trap pair was suspended from a floating rope anchored to the lake shore and intersecting the two-meter isobath at the sampling point. The sampling points along the $2 \mathrm{~m}$ isobaths was randomly generated in the $\mathrm{R}$ environment $(\mathrm{R}$ 3.1.1) using the function "readshapeSpatial" (package "maptools") to import the shape file of the $2 \mathrm{~m}$ isobaths and the function "runifpointOnLines" (package "spatstat") to generate four random points (R Development Core Team 2013). The point generation was repeated three 
168 times in each lake to generate a sufficient number of random points to change the position of

169 the trap pairs at each sampling session. The water level of most of the lakes was constant, but

170 NER and NII can undergo a water level reduction (approximately $1 \mathrm{~m}$ in NER, and $1.5 \mathrm{~m}$ in

171 NII) during the summer. However, the water level fluctuation was not detectable over a daily

172 or weekly period and did not affect the vertical displacement of the traps.

173 The sampled insects were removed from the traps and fixed in $70 \%$ ethanol directly in the

174 field. The samples were sorted under a stereomicroscope at a magnification of 10x, classified

175 at the order level, enumerated, and their maximum body length was measured.

Number and biomass of terrestrial arthropods sinking into the lakes

178 The captures of terrestrial arthropods from funnel traps were used to estimate the number (No. $\times \mathrm{m}^{-2} \times$ day $^{-1} \pm 95 \%$ Confidence Intervals) and dry biomass $\left(\mathrm{mg} \times \mathrm{m}^{-2} \times\right.$ day $^{-1} \pm 95 \%$

Confidence Intervals) of terrestrial arthropods sinking into the lakes. Arthropod dry biomass was calculated from order-specific length-biomass relationships (Sabo et al. 2002). These estimates were also multiplied by the lake surface area to obtain a gross daily estimate of the arthropods falling into each lake $\left(\times\right.$ lake $^{-1} \times$ day $\left.^{-1}\right)$, despite being aware that input of airborne particles could depend on the distance from the shoreline (Psenner 1984; Cole et al. 1990; but see Norlin 1964, 1967 and Cole et al. 1990 showing that this relation is weak or inexistent for terrestrial arthropods and the next paragraph for the description of a dedicated field test).

Number of sinking arthropods and distance from the shoreline

The number of sinking arthropods could vary on the lake surface: intuitively, compared to the pelagic area the littoral area should be the recipient of a larger number of falling arthropods.

191 To check how the measures from the sublittoral zone (at the $2 \mathrm{~m}$ isobaths) compare with the 192 measures from the littoral and pelagic zone, we designed a specific field test. Between June 
$19326^{\text {th }}$ and August $31^{\text {st }}, 2016$, we performed 7 repeated sampling in lake DRE to understand if

194 the distance from the shoreline influence the number of arthropods (No. $\times \mathrm{m}^{-2} \times$ day $^{-1}$ )

195 sinking into the lake. DRE is one of the "eradication" lakes and in 2016 was already fishless.

196 This lake was chosen because of its lower altitude and warmer microclimate, potentially

197 favoring insect production. During each sampling session, two plots of traps were suspended

198 along two transects (floating ropes) perpendicular to the lake shore, one in N-S direction and

199 the other one in E-W direction. Each plot had four traps placed approximately five cm below

200 the water surface at 0 (with the border of the trap in contact with the shoreline), 1, 10, $20 \mathrm{~m}$

201 from the shoreline. Each sampling session lasted for 3-5 days. The sampled arthropods were

202 removed from the traps and fixed in $70 \%$ ethanol directly in the field. The samples were

203 sorted under a stereomicroscope at a magnification of $10 \mathrm{x}$, classified at the order level, and

204 enumerated.

205

Timing of underwater disappearance of terrestrial arthropods

207 The decomposition timing of the terrestrial arthropods captured in the funnel traps may be too 208 rapid and affect the validity of the sampling results. We therefore performed a field test to 209 assess the decomposition time in four insect categories: small (total length $<5 \mathrm{~mm}$ ) and large

210 ( $>5 \mathrm{~mm}$ ) highly chitinized insects (adult terrestrial Coleoptera and Heteroptera), and small

$211(<5 \mathrm{~mm})$ and large $(>5 \mathrm{~mm})$ poorly chitinized insects (adult terrestrial Diptera). While we

212 are aware that decomposition process could quickly affect soft tissues and arthropods

213 biomass, the specific objective of this field test was understanding if all the arthropods could

214 be easily recognized as such at the end of each sampling session. The insects used in the test

215 were captured in the field using a hand-net, euthanized with low temperature, and preserved

216 at $-18^{\circ} \mathrm{C}$ until the beginning of the test on the $28^{\text {th }}$ June, 2016 . We submerged 5 insects per

217 category into transparent plastic boxes closed with a net (1 $\mathrm{mm}$ mesh-size) together with two 
temperature loggers (measuring interval: 1 hour) at 0 and $6 \mathrm{~m}$ depth (using the vertical temperature gradient to simulate two temperature treatments) into Lake DRE. We checked the box content every 4-5 days for the first 15 days and then two weeks later (at day 28) and we took note of the state of decomposition of the different insect categories. Lake DRE was chosen because, compared to the other study lakes, it presents relatively high water temperatures and bacterial load (Tiberti et al. 2014b), therefore providing cautionary short times of degradation of the organic matter.

\section{Statistical analyses}

To test H1 we used the counts of terrestrial arthropods (response variables) collected in 2013 with the paired benthic and surface funnel traps. We applied a Bayesian generalized mixed model for count data (GLMM) with Markov-chain Monte-Carlo (MCMC) estimation, using package 'MCMCglmm' (Hadfield, 2010) in the statistical environment R v.3.1.1 (R Development Core Team 2013). We included two additive random effects: the lake (to account for the variation attributable to the sampling site) and a grouping variable distinguishing all the counts pairs coming from each plot of paired traps. The lakes' stocking history (Treatment: Fish-N: naturally fishless lakes; Fish-Y: lakes with fish; Fish-E: Eradication lakes), the sampling depth (Depth: surface vs. bottom), their interaction (Treatment-by-Depth), and the sampling effort (Days: duration of the sampling in days) were added as fixed factors. The Posterior Marginal $\mathrm{R}_{\mathrm{GLMM}}^{2}$ and $95 \%$ Credibility Intervals were calculated following Nakagawa and Schielzeth (2013) to measure the goodness of fit of the model. H1 is verified when the posterior mean estimates of Treatment-by-Depth are significantly lower in the presence of fish than in the eradication and fishless lakes (meaning that the fish presence is reducing the proportion of terrestrial arthropods reaching the benthic traps). Because most funnel traps in our study (nearly 71\%) had no arthropods, and because 
243 these zero values cannot be clearly ascribed to absence data, we used a zero-altered Poisson 244 (ZAP) GLMM (Hadfield, 2015). ZAP models contain two sub-models: one related to the 245 zeroes and one related to counts greater than zero. Therefore, the model results depend on 246 two latent variables: (i) the probability (in logit scale) of the response variable being non247 zero, which is here interpreted as the probability of sampling at least one arthropod in the 248 traps, and (ii) the mean parameter of a zero-truncated Poisson distribution, which in this case 249 corresponds to the estimated arthropod count in non-empty traps.

250 Since data did not met the assumption for parametric tests, we performed a non-parametric 251 Kruskal-Wallis test to determine if the distance from the shoreline influences the number of 252 terrestrial arthropods sinking into the lakes $\left(\mathrm{N} \times \operatorname{trap}^{-1} \times\right.$ day $\left.^{-1}\right)$ with the distance from the coast $(0,1,10,20 \mathrm{~m})$ as grouping factor.

Daily consumption of terrestrial insects

For each lake treated for fish eradication we estimated absolute fish abundance, and built a simple terrestrial arthropod consumption model. The model parameters were estimated from original data on the brook trout abundance, size structure, and diet and from literature data on the brook trout Gastric Evacuation Rates (GER, the speed with which food leave the stomach after ingestion). Since GER for brook trout is dependent on water temperature (Sweka et al. 2004) we respectively used its minimum and maximum values to account for the uncertainty of this parameter (GER values from literature data; Sweka et al. 2004; Forester et al. 1994; Boisclair and Sirois 1993) to obtain a raw but realistic range of variation of arthropod consumption under different temperature regimes. The models output are four ranges of variation (one per lake) of terrestrial arthropod consumption (both in terms of abundance and biomass), and were compared with the measured numbers and calculated biomasses of 267 sinking arthropods to test H2. 
Daily Consumption of Terrestrial Arthropods (CTA) by the fish population has been calculated separately for each lake DJO, DRE, LEY, and NER and is described by:

$274 \quad \mathrm{CTA}=24 \times \mathrm{GER} \times \sum_{\mathrm{c}=1}^{4} N F_{c} \times T A_{c}$

276 Where $\mathrm{NF}_{\mathrm{c}}$ denotes the number of fishes belonging to size class $\mathrm{c}$, with c varying from 1 to 4 277 (from $<15$ to $\geq 25 \mathrm{~cm}$ at $5 \mathrm{~cm}$ intervals). GER denotes the Gastric Evacuation Rate, considered as constant whatever the size class. We used the minimum and maximum GERs measured for brook trout in laboratory $\left(0.005-0.080 \mathrm{~h}^{-1}\right.$; Boisclair and Sirois 1993; Forester et al. 1994; Sweka et al. 2004) to obtain a reliable CTA range. $\mathrm{TA}_{\mathrm{c}}$ denotes the average number of terrestrial arthropods in the stomach contents of a fish belonging to size class c. To estimate TA we had to take into account that the consumed terrestrial arthropods could also be emerging insects with aquatic pre-imaginal stages, captured at their emergence. It was therefore inappropriate to consider all of them as terrestrial prey falling into the water. Conservatively, we decided to exclude all the potentially emerging insects from the CTA estimates. We divided the consumed terrestrial arthropods into three groups. Group 1 includes the arthropod orders without aquatic stages (e.g. Araneae, Opiliones, Lepidoptera, Orthoptera, terrestrial Coleoptera, terrestrial Hemiptera); they were included in the TA estimate. Group 2 includes the insect orders with terrestrial imaginal stages, but aquatic pre290 imaginal stages (Trichoptera, Plecoptera, Ephemeroptera, Odonata); they were excluded from 291 the TA estimate. Group 3 includes terrestrial Diptera and Hymenoptera, which, due to the 292 close resemblance of many of their families (e.g. Syrphidae closely resemble Hymenoptera), 
293

294

295

296

297

298

299

300

301

302

303

304

305

306

307

308

309

310

311

312

313

314

315

316

were clumped into a single prey-group during most of the diet analyses. However, Diptera comprise some families with terrestrial pre-imaginal stages (e.g. Muscidae, Bombiilydae, Drosophilidae) and some others with aquatic or potentially aquatic pre-imaginal stages (e.g. Chironomidae, Tabanidae, Limoniidae, Tipulidae).

For each size class c, TA is described by:

$\mathrm{TA}=\frac{1}{n} \times \sum_{k=1}^{n}\left[\operatorname{Ngroup}_{k}+\left(a \times \operatorname{Ngroup}_{k}\right)\right]$

Where $n$ is the total number of fishes belonging to a size class, and $k$ an individual. Ngroup $_{k}$ and $\operatorname{Ngroup}_{k}$ are the number of arthropods belonging to the corresponding groups found in the stomach content of one individual $k$, and $a$ denotes the estimated proportion of insects belonging to the prey group 3 (adult Diptera/Hymenoptera) with terrestrial pre-imaginal stages (including part of the Diptera and all the Hymenoptera). We therefore performed 40 additive stomach contents analysis, with the specific aim of estimating $a$ :

$a=\frac{\operatorname{Ngroup}_{\text {sub }}^{\prime}}{\operatorname{Ngroup} 3_{\text {sub }}}$

Where Ngroup3'sub represents the cumulative number of Diptera/Hymenoptera with terrestrial pre-imaginal stages found in the subsample of stomach contents, and $N g r o u p 3_{\text {sub }}$ represents the total number of Diptera/Hymenoptera found in the same stomach contents subsample.

Contrary to the insects belonging to group 2, which are an occasional trophic resource for brook trout, Diptera/Hymenoptera are a very common prey item (Tiberti et al. 2016). Therefore, a correct estimate of coefficient $a$ is likely to appreciably influence the CTA estimates. Coefficient $a$ is considered constant whatever the size class. 
317 Prey biovolume measurements were used to convert CTA ranges into biomass values

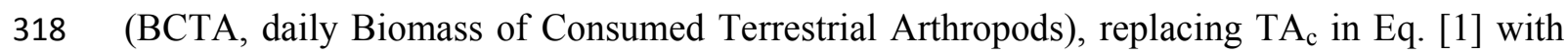
$319 \mathrm{VTA}_{\mathrm{c}}$ :

320

321

$\mathrm{BCTA}=24 \times \mathrm{GER} \times \sum_{\mathrm{c}=1}^{7} N F_{c} \times V T A_{c}$

322

323 Where $\mathrm{VTA}_{\mathrm{c}}$ denotes the average biovolume of terrestrial arthropods in the stomach contents of a fish belonging to size class $\mathrm{c}$ and is described by:

325

326

$\mathrm{VTA}=\frac{b}{n} \times \sum_{k=1}^{n}\left[\operatorname{Vgroup} 1_{k}+\left(a \times \operatorname{Vgroup} 3_{k}\right)\right]$

327

For the same reasons explained for Eq. [2], only the biovolumes (V) of the terrestrial arthropods without preimaginal aquatic stages -those belonging to group 1 (Vgroup1) and a fraction of those belonging to group 3 (Vgroup3)- were included in Eq. [5]. Biovolumes were converted to dry weight by multiplying by a constant value (b) equal to 0.35 according to Studier and Sevick (1992), who assessed that the water content of a wide range of terrestrial arthropods is approximatively the $65 \%$ of their live weight.

Fish abundance and size-structure: parameter estimates

336 To estimate $\mathrm{NF}_{\mathrm{c}}$ we used the fish abundance and total length measures obtained at the end of 337 the eradication campaign in Lakes DJO, DRE, LEY, and NER. Fish abundance was 338 accurately measured along the eradication campaign. Intensive gill-netting was used as 339 eradication method in the sub-littoral and pelagic area, while electrofishing (with a ELT62 II 340160 GI backpack equipment) was used to remove the fish from the littoral area and tributaries 341 (Knapp and Matthews 1998). In addition, two days of experimental intensive angling had 
342 already substantially contributed to the decline of the population in Lake DRE, just before the 343 start of the eradication campaign (Tiberti et al. 2017). The length of the brook trout removed 344 from the lakes was usually recorded, but not for fish in advanced state of decomposition (e.g. 345 many fish removed at the end of the ice-cover seasons). We therefore assigned those fish to 346 one of four size classes encompassing the values from $<15 \mathrm{~cm}$ to $>25 \mathrm{~cm}$ at $5 \mathrm{~cm}$ intervals.

347 For a few fish it was not even possible to assign a size class and they were therefore assigned 348 to the different classes proportionally to the relative abundance of each size class.

349 Fish growth from one season to the next is relevant for the model parameterization since the 350 allocation of one fish to its size class would require a back-calculation of the fish size at a 351 reference date. However, due to the presence of missing data in the length measurements, a 352 precise back-calculation (based on age-length literature data or scalimetric/otholith ring 353 measures; Panfili et al. 2002) was not feasible. We therefore decided to account for fish 354 growth reducing by one unit the size class of those fish captured during the second field 355 season (2014, including the 2014-2015 ice cover season), and by two units the size class of those fish captured during the third field season (2015, including the 2015-2016 ice cover season). This seems a fair realistic adjustment of the data. Indeed, the very large majority of fish captured during the second and third field seasons were young fish, hatched from their nests the previous year, while the large majority of $>15 \mathrm{~cm}$ fish $(100.0 \%$ in DJO; $99.6 \%$ in DRE; 97\% in LEY; 98.9\% in NER) were captured during the first field season. As a result, only the densities of size class $1(<15 \mathrm{~cm})$ are substantially affected (reduced) by this kind of 362 data adjustment; in particular those fish $<15 \mathrm{~cm}$ captured during the second field season and those fish $<20 \mathrm{~cm}$ captured during the third field season have been removed from the total count of captured fish, because they probably were not present (not born) during the first year. On the other hand, the densities of larger size classes, which were redly removed from the lakes during the first field season, are almost unaffected. 
Fish diet: parameters estimates

To estimate $\mathrm{TA}_{\mathrm{c}}$, between 2006 and 2016 we collected 306 stomach contents (from both daytime and nighttime sampling sessions; 61 in June, 74 in July, 121 in August, 50 in

372 (see Tiberti et al. 2016 for detailed analytical methods). Ingested items were divided into aquatic and terrestrial prey, classified in the different ecological groups 1-3 and sub-groups

374 (see, and enumerated. In addition, the biovolume of each different prey item was measured 375 from a subsample of 236 stomachs to estimate $\mathrm{VTA}_{\mathrm{c}}$ by gently pressing the prey items belonging to each prey group in a graduated cylinder. Prey groups with very small biovolumes $(<0.05 \mathrm{~mL})$ were approximated to zero.

\section{Results}

Sinking arthropods

Proportion of arthropods reaching the bottom: paired traps experiment

384

To test H1, we collected 232 samples (116 trap pairs) for sinking arthropods from 10 lakes. Three traps pairs were discarded because the content of at least one of the two traps was totally or partially lost during the collection. After 4-12 days of sampling, 160 out of 226 traps did not contain terrestrial arthropods. During the whole sampling campaign, a total of 106 terrestrial arthropods (mean \pm SD per trap: $0.47 \pm 0.95 ; 74$ Diptera, 27 Coleoptera, 3 Araneae, 1 Hymenoptera, 1 Tricoptera) were collected.

MCMCglmm results showed that the number of terrestrial arthropods directly depends on the duration of the sampling, while it is not significantly different in the traps placed at different 
392 depths, and among the lakes with different stocking histories (Table 3). The interactive effect

393 of Treatment-by-Depth showed very limited evidence in favor of H1, i.e. we found a

394 significantly higher proportion of terrestrial arthropods reaching the bottom in eradication

395 lakes than in the lakes with fish, but the same proportion was not significantly different

396 between lakes without fish and lakes with fish or treated for fish eradication (Table 3). In

397 spite of the relatively large number of samples, the statistical model showed a low goodness

398 of fit [Posterior Marginal $\mathrm{R}_{\text {GLMM }}(95 \%$ Credibility Intervals $\left.)=0.17(0.03-0.54)\right]$, probably

399 due to the small number of sinking arthropods.

400 Since the difference between the number of sinking arthropods captured at the lake surface

401

402

403

404

405

406

407

408

409

410

411

412

413

414

415

416

and bottom was not significant, we used the data from both the surface and bottom traps to

estimate the flux of sinking arthropods in each lake (Table 2). We found that the number and

biomass of sinking arthropods was highly variable among lakes with a range of 0.02 to 1.40

invertebrates $\mathrm{m}^{-2} \times$ day $^{-1}$ and 0.0 to $4.3 \mathrm{mg} \times \mathrm{m}^{-2} \times$ day $^{-1}$ (ANOVA results for arthropod

abundance: $\mathrm{F}_{9,216}=10.6, \mathrm{p}<0.0001$; ANOVA results for arthropod biomass: $\mathrm{F}_{9,216}=5.0$,

$\mathrm{p}<0.0001$; Table 2).

\section{Sinking arthropods and distance from the shore}

Of the 56 traps surveys ( 8 traps $\times 7$ replicates), only 9 traps contained terrestrial arthropods. In total, 16 insects (8 Hymenoptera, 5 Diptera, and 3 Coleoptera) were collected in Lake DRE, corresponding to a mean \pm SD capture rate of $0.34 \pm 0.85$ sinking arthropods $\times \mathrm{m}^{-2} \times$ day $^{-1}$. The capture rates were $0.66 \pm 1.19$ sinking arthropods $\times \mathrm{m}^{-2} \times$ day $^{-1}$ at $0 \mathrm{~m}$ from the shoreline; $0.60 \pm 1.08$ sinking arthropods $\times \mathrm{m}^{-2} \times$ day $^{-1}$ at $1 \mathrm{~m}, 0.00 \pm 0.00$ sinking arthropods $\times \mathrm{m}^{-2} \times$ day $^{-1}$ at $10 \mathrm{~m} ; 0.07 \pm 0.27$ sinking arthropods $\times \mathrm{m}^{-2} \times$ day $^{-1}$ at $20 \mathrm{~m}$. These results suggest a negative relationship between the distance from the shoreline and the number of sinking arthropods, but the relationship was not significant (Kruskal-Wallis test $=6.91$, $\mathrm{df}=$ 
$4173, \mathrm{p}=0.07$ ) and the number of sinking arthropods remained very low even close, or in contact,

418 with the shoreline. The measures recorded during this field test were also comparable with

419 those recorded during the 2013 sampling campaign in the sublittoral area (Table 2).

420

421 Time of arthropods degradation

422 Insects from all four categories were exposed for 28 days $\left(28^{\text {th }} \mathrm{June}-26^{\text {th }} \mathrm{July}, 2016\right)$ at a 423 mean water temperature of $10.5^{\circ} \mathrm{C}$ (range: $6.7-16.3{ }^{\circ} \mathrm{C} ; 0 \mathrm{~m}$ depth) and $8.6^{\circ} \mathrm{C}$ (range: $6.2-$

$42411.5^{\circ} \mathrm{C} ; 6 \mathrm{~m}$ depth; Fig. 3). After the settlement of the cages containing the insects, the state 425 of decay of the insects was repeatedly checked. Until day 15 (which exceed by 3 days the 426 maximum sampling time of the funnel traps) all the insects were still perfectly recognizable;

427 by day 28 some insects showed clear signs of decay (loss of wings or elytra), but all large 428 insects and the majority of small insects were still well recognizable in both temperature 429 treatments.

430

CTA models: parameters and outputs

Fish abundance and size-structure

434 The density, abundance and size class distribution of the fish removed from the four lakes treated for fish eradication were highly variable (Table 4). Since fish eradication was completed in all the lakes, the estimates of fish population parameters are precise. In all the

437 lakes more than 1 year have passed without any fish capture: DJO (last fish removed on 14/06/2014), DRE (last fish removed on 11/08/2015), LEY (last fish removed on 05/06/2016)

439 and NER (last fish removed on 07/06/2015).

440

441 Terrestrial arthropods in the fish diet and coefficient " $a$ " 
442 Terrestrial arthropods are commonly preyed upon by lake dwelling brook trout. In terms of 443 relative abundance, terrestrial arthropods were moderately important diet items for the brook 444 trout, ranging from $4-8 \%$ of the relative abundance of prey in size classes $1-3$, but reaching $44545 \%$ for size class 4 (Table 5). In terms of ingested biovolumes, terrestrial arthropods represented a substantial part of the diet of all the size classes and they are by far the 447 dominant component of the diet of larger brook trout (Table 4). The analysis of 40 additive 448 stomach contents showed that the proportion of terrestrial Diptera/Hymenoptera (group 3) 449 with terrestrial pre-imaginal stages is 0.61 (coefficient "a").

\section{CTA Models outputs}

452 The model parameters are summarized in Table S1 of the online supplementary material S1.

453 For the calculation of the daily consumption of terrestrial arthropods, the relevant fish

454 frequencies are those obtained accounting for annual growth: the differences between the 455 observed frequencies of Table 4 and the estimated frequencies used to parametrize the model and reported in Table S1 have to be ascribed to the data adjustment.

457 CTA model outputs returned a range of daily Consumption of Terrestrial Arthropods for each lake which was divided by the lake surface to obtain the consumption $\times \mathrm{m}^{-2}$ (Fig. 4). In Lake DJO the brook trout population consumed $2435-38955$ terrestrial arthropods $\times$ day $^{-1}$ corresponding to $0.2-2.9$ arthropods $\times$ day $^{-1} \times \mathrm{m}^{-2}$ equal to a dry biomass of $1.8-28.4 \mathrm{mg} \times$ day $^{-1} \times \mathrm{m}^{-2}$; in Lake DRE the brook trout population consumed $8685-138960$ terrestrial arthropods $\times$ day $^{-1}$ corresponding to $0.3-5.3$ arthropods $\times$ day $^{-1} \times \mathrm{m}^{-2}$ equal to a dry biomass 463 of $6.3-101.0 \mathrm{mg} \times \mathrm{day}^{-1} \times \mathrm{m}^{-2}$; in Lake LEY the brook trout population consumed $3921-$ 464 62744 terrestrial arthropods $\times$ day $^{-1}$ corresponding to $0.1-1.4$ arthropods $\times$ day $^{-1} \times \mathrm{m}^{-2}$ equal to a dry biomass of $2.7-43.8 \mathrm{mg} \times$ day $^{-1} \times \mathrm{m}^{-2}$; in Lake NER the brook trout population consumed $881-14094$ equal to terrestrial arthropods $\times$ day $^{-1}$ corresponding to $0.1-0.8$ 
467 arthropods $\times$ day $^{-1} \times \mathrm{m}^{-2}$ equal to a dry biomass of $0.7-11.5 \mathrm{mg} \times$ day $^{-1} \times \mathrm{m}^{-2}$. The very high

468 variability of the arthropods consumption estimates among the "eradication lakes" mainly

469 depends on the total abundance of fish inhabiting the lakes, which can vary from a few

470 hundred in Lake NER to several thousands in Lake DRE.

471

472 Comparison between sinking arthropods and consumption by fish

473 The number/biomass of sinking and consumed arthropods $\times \mathrm{m}^{-2}$ can overlap when the GER is

474 low, while arthropods consumption can exceed several folds the Upper 95\% CI of the

475 number/biomass of sinking arthropods when the GER is kept high (Fig. 4). The gap between

476 sinking and consumed arthropods is comparatively larger in terms of biomass than in terms of

477 abundance (Fig. 4).

478

479 Discussion

480

481 Number of sinking arthropods and their proportion reaching the bottom

482

483

484

485

486

487

While terrestrial arthropod deposition in lotic ecosystems is well documented (e.g. Mason and MacDonald 1982; Bartels et al. 2012) there are considerably fewer studies from lentic ecosystems, and the deposition of arthropods onto lake surfaces remains relatively unknown (Wurtsbaugh 2007). The few existing data describe occurrence on the lake surfaces (Norlin 1964, 1967; Childress et al. 1981; Bowman 1988), or have to be extrapolated from studies dealing with the deposition of terrestrial particles -including arthropods- over the lakes (e.g.

489 Cole et al. 1990). To the best of our knowledge, the present study is the first attempt to 490 measure the quantity of arthropods sinking into lacustrine ecosystems. Therefore, we do not 
491 have any reference to understand how the measured numbers of sinking arthropods compare 492 with those from other lakes.

493 In the present study, the sedimentation traps operated near their detection limit and the 494 estimates they provided (in the order of 0-2 organisms $\times \mathrm{m}^{-2} \times$ day $^{-1}$ ) were far lower than our initial expectations founded on the observation that terrestrial arthropods drifting on the lake surface can appear very abundant. However, repeated sampling in several lakes seems appropriate for estimating the number of sinking arthropods. The only factor which could affect the validity of these measures is the removal/disappearance of arthropods from the traps, which can be determined either by decay -though we demonstrated that their disappearance requires more time than the sampling periods- or by their mechanic removal from the traps, i.e. by predation. However, the number of sinking arthropods remained low in all lake categories, particularly in fishless lakes and in "eradication lakes" (where fish densities had strongly decreased and invertebrate predators, e.g. aquatic Coleoptera, had not yet recovered), suggesting that fish and invertebrates feeding inside the traps is not of major significance.

Therefore, we tested how the estimated numbers of sinking arthropods in the sublittoral zone compare with the corresponding numbers in the littoral and pelagic zone, by placing the traps at different distances from the shoreline. The underlying idea was that many arthropods trapped at the lake surface are transported by wind to the shoreline (Norlin 1967), where they end up sinking and where we were expecting a disproportionate higher number of sinking arthropods. However, in Lake DRE we found marginally significant higher number of sinking arthropods close to the shoreline compared to the pelagic zone, and the recorded measures overlapped the measures in the sublittoral zone. This result is similar to that

514 reported by Norlin $(1964,1967)$ and Cole et al. (1990), who did not find a correlation 515 between insects falling onto a lake surface and distance from shore. Overall, the number of 
516 sinking arthropods remain low, even close or very close to the shoreline, and the idea of a

517 massive sink of arthropods along the shore is not supported by our data.

518 Even if there is not much known about the magnitude and spatial patterns of insect deposition

519 to lakes, a few studies suggest that the origin of insect fallouts to lakes is mainly the

520 surrounding shoreline (Norlin 1967; Mehner et al. 2005) and the low number of sinking

521 arthropods could be explained by the absence of shoreline vegetation, which enhance the

522 fallout of terrestrial particulate matter and arthropods (e.g. Nakano and Murakami 2001;

523 Piovia-Scott et al. 2016). However, arthropod falling onto lake surface could also derive from

524 the aerial plankton that can drift considerable distances (Cusimano et al. 2016) and which fall

525 or sink all over lakes, not just near the shoreline (Norlin 1967; Wurtsbaugh 2007).

526 Concerning H1, we did not find any significant effect of the presence of fish on the

527 abundance of sinking insects, nor a clear effect on the proportion reaching the lake bottom.

528 This result is very counterintuitive, because of the large number of insects consumed by the

529 fish populations (Table 5; Tiberti et al. 2016). Even if we collected a large number of samples

530 from several lakes, we attribute this result to a weakness of our sampling design: the low

531 number of sinking arthropods produced a large number of empty traps, affecting the power of

532 the statistical models. The very low proportion of variance explained by the model is

533 indicative of an inadequate sampling and suggests that $\mathrm{H} 1$ should not be rejected despite

534 these results.

535

536 Sinking arthropods, fish consumption and water surface tension

537 The finding that, compared to the values recorded in the sublittoral zone, the number of

538 sinking arthropods is low also along the shoreline, encouraged us to tentatively use the

539 estimates from the sublittoral zone as a reasonably realistic estimate of the number of sinking

540 arthropods into the lake as a whole. This number probably represents an intermediate value 
541 between the lower values of the pelagic zone and the slightly higher values of the littoral

542 zone. The entire lake estimates can be compared with the consumption rates by the

543 introduced fish populations from the lakes treated for fish eradication (for which absolute

544 abundance, size structure, and dietary data were available) to test $\mathrm{H} 2$.

545 Before proceeding to the discussion of the comparison between sinking and consumed

546 arthropods, it should be emphasized that the output of the food consumption models likely

547 provides an underestimate of the number/biomass of arthropods falling onto the lakes'

548 surface because: i) the consumption rates depend on the maximum consumption capacity of

549 the fish populations (which strongly vary with water temperature) and are a measure of the

550 minimum availability of terrestrial arthropods, and ii) the consumption rates were cautiously

551 calculated keeping some parameters low (e.g. excluding the insect belonging to the prey

552 group 2 and part of the insects of group 3; Table 4).

553 Considering the abundance of sinking arthropods, the output of the consumption models

554 supported H2 under high GERs. Indeed, the number of sinking arthropods can overlap the

555 number of consumed arthropods when the GER is kept low, but arthropods consumption can

556 largely exceed the number of sinking arthropods when the GER is kept high (Fig. 4). On the

557 other hand, fish usually consume a much larger biomass of arthropods than that of sinking

558 arthropods (Fig. 4), likely due to the size selective behavior of introduced brook trout (Tiberti

559 et al., 2014a) and the model output generally support H2 independently by the GERs values.

560 The lower values of the abundance/biomass ranges are representative of the consumption

561 rates under low water temperatures (minimum GER value was calculated at $2^{\circ} \mathrm{C}$; Sweka et al.

562 2004), while the higher values are representative of the consumption rates under warmer

563 conditions (the GER reach an asymptotic maximum at $\approx 12^{\circ} \mathrm{C}$; Sweka et al. 2004). Both the

564 temperatures fall into the range of surface temperatures commonly registered during the ice-

565 free period in the study lakes (Tiberti et al. 2010). Larger consumption estimates are expected 
566 to be representative of the central part of the ice-free season (temperatures $>12^{\circ} \mathrm{C}$ are

567 commonly registered at the lakes' surface in July-September), while lower consumption

568 estimates are expected to occur at thaw and before freezing (October). Arthropod

569 consumption depends also on the fish population abundance and size structure, and the lower

570 range of arthropod consumption was found in Lake NER, where the fish population has a

571 very low abundance ( $\approx 200$ fish).

572 The arthropods consumed by fish can exceed the number of sinking arthropods and they can

573 have different origins: i) they can be predated by brook trout before falling into the water:

574 brook trout can capture some groups of slow insects when they are near the lakes surface, i.e.

575 butterflies (authors personal observations), but this kind of predation is certainly exceptional;

576 ii) they can be floating arthropods fallen onto the lake surface and drifting on the lakes

577 surface; iii) they can come from the tributaries: in Lakes NER and DJO, tributaries are absent

578 or very short $(\approx 100 \mathrm{~m})$ and it seems very unlikely that a significant number of insects could

579 come from inflowing streams. By the way this source could be more important in Lake LEY

580 and in Lake DRE, presenting permanent tributaries extending for $>1000 \mathrm{~m}$. However,

581 according to Clifford (1972), more than the $90 \%$ of the terrestrial invertebrates drift at the

582 stream surface. Therefore, even assuming that drift from the tributaries represents a

583 substantial part of the terrestrial prey consumed by lake dwelling brook trout, most of the

584 insects carried by the rivers are intended to float over the lakes' surface, apparently without

585 sinking.

586 Owing to the disproportion between the few sinking arthropods and the many terrestrial

587 arthropods consumed by fish, we concluded that the fate of most of the arthropods falling into

588 the water is not to sink. Our results suggest that when terrestrial arthropods are not eaten by

589 aquatic predators, they often leave the aquatic environment: they can be washed on to the

590 land (depending on the configuration of the shore), drift downstream on the outflowing river 
591 surface, or survive and fly away. The ability of terrestrial arthropods to survive a period in the 592 water has been documented and most species may resist floating for several days or weeks 593 (Norlin 1967; Coulson et al. 2002). Contrary to our finding, it is commonly assumed that 594 nearly all terrestrial insects fallen into the lakes become part of the nutrient budget of the lake 595 (Mehner et al. 2005; Mehner et al. 2007; Wurtsbaugh 2007). The results of the present study 596 demonstrate that this assumption is unfounded and that many insects that fall into the lake, if 597 they are not preyed upon by fish, would ultimately leave the lakes and return to the terrestrial 598 environment. For example, Menher et al. (2007), in accordance with Wurtsbaugh (2007), 599 state that fish are not irreplaceable agents in making external nutrients bound in terrestrial insects available to the lake and that lakes are sinks for these nutrients even if they do not harbor insectivorous fishes. In the light of our results we believe that many terrestrial arthropods falling into the lakes would not contribute to the nutrient budget of the lakes if fish predation does not allow them to cross the water-air interface, preventing them from leaving the lakes. Consistent with our findings, the few times that number of arthropods falling upon the surface of lentic habitats have been estimated their abundance/biomass was dramatically larger than what we observed with the sinking traps (16-126 arthropods $\times \mathrm{m}^{-2} \times$ day $^{-1} ; 16-93$ $\mathrm{mg} \times \mathrm{m}^{-2} \times$ day $^{-1}$; Bowman 1988). Childress et al. (1981) found similar arthropods biomass values of Bowman (1988), without providing the number of arthropods (but note that both the 609 study sites are not high mountain lakes).

610 Although terrestrial arthropods are not likely to be an important subsidy to nutrient budgets of lakes (Childress et al. 1981; Vander Zanden and Gratton 2011), the idea that surface tension

612 is a major barrier and that -depending on the presence of predatory fish- incoming arthropods 613 might be pushed back to the lake edges or drawn into the water column by fish, could have 614 interesting consequences for understanding the nutrient supply to lakes provided by terrestrial 615 arthropods. In this context fish can also assume the role of a net source of terrestrial 
616 subsidies, diverting to the water column the nutrients contained in many arthropods whose

617 fate was not entering into the lakes. For example, Mehner et al. $(2005,2007)$ reported that the 618 diet of a lake dwelling population of bleak (Alburnus alburnus) was dominated by terrestrial 619 insects ( $~ 84 \%)$, with potential impacts on the nutrient budget of the lake.

620 We summarized the possibility for many arthropods to leave (dead or alive) the aquatic

621 habitat into the conceptual scheme of Fig. 5, where the role of fish as vector for terrestrial 622 arthropods across habitat boundaries is highlighted. Fig.5 also shows that there are several 623 pathways through which arthropods can enter and leave lakes and that further studies need to 624 include these pathways.

625 From a conservation point of view, our results imply that, if fish introduced in mountain lakes 626 consume the arthropods drifting on the lakes surface, their abundance in the benthic zone and 627 in the littoral area (when they are washed out from the lakes) decreases. The floating insects 628 which are diverted to introduced fish and cannot leave the aquatic habitat are subtracted to 629 the terrestrial habitat and terrestrial consumers (e.g. terrestrial insectivores), possibly 630 exacerbating the competition between terrestrial insectivores and introduced fish for aquatic 631 subsidies (emerging insects; Finlay and Vredenburg 2007; Epanchin et al. 2010; Joseph et al. 632 2011; Piovia-Scott et al., 2016) and representing a further overlooked component of the 633 reciprocal resource subsidies between mountain lakes and terrestrial habitats (see the 634 conceptual model of reciprocal resource subsidies in Piovia-Scott et al., 2016).

636 Aknowledgements

637 The authors thank Bruno Bassano, Achaz von Hardenberg, Ramona Viterbi (GPNP), and 638 Giuseppe Bogliani (University of Pavia) for their commitment to research in the GPNP. 639 Special thanks to the Park wardens, Stefano Malaguti, Giovanni Cecioni, Jean Laurent 640 Jordaney, Andreu Porcar, Gioele Grandi for their help during the fieldwork, and to Ben 
641 Whittaker for his kind linguistic revision. Many tanks to an anonymous reviewer for many 642 helpful comments. Funding and logistic support for this research was provided by the GPNP 643 within the framework of the LIFE+ project BIOAQUAE (Biodiversity Improvement of 644 Aquatic Alpine Ecosystems, LIFE11 BIOIT000020). Permissions for fishing activities have 645 been issued by the GPNP (protocol number 1798/1013/BB) with the approval of ISPRA 646 (Istituto Superiore per la Protezione e Ricerca Ambientale, protocol number 0017655 $64729 / 04 / 2013)$.

References

Bartels, P., Cucherousset J., Steger, K., Eklöv, P., Tranvik, L.J., and Hillebrand, H. 2012. Reciprocal subsidies between freshwater and terrestrial ecosystems structure consumer resource dinamics. Ecology 93(5):1173-1182. doi:10.1890/11-1210.1

Bloesch, J., and Burns, N.M. 1980. A critical review of sedimentation trap technique. Schweiz. Z. Hydrol. 42(1):15-55.

Boisclair, D., and Sirois, P. 1993. Testing assumptions of bioenergetics models by direct estimation of growth, consumption, and activity rates. Trans. Am. Fish. Soc. 122(5):784-796. doi:10.1577/1548-8659(1993)122<0784:TAOFBM>2.3.CO;2

Bowman, T.E. 1988. The input of terrestrial insects and spiders to the nutrient cycle of a woodland pond. Entomol. News 99:207-2 16.

Carlton, R.G., and Goldman, C.R. 1984. Effects of a massive swarm of ants on ammonium concentrations in a subalpine lake. Hydrobiologia 111(2):113-117. doi:10.1007/BF00008623

Carpenter, S., Cole, J., Pace, M., Batt, R., Brock, W., Cline, T., Coloso, J., Hodgson, J., Kitchell, J.F., Seekell, D.A., Smith, L., and Weidel, B. 2011. Early Warnings of 
665

666

667

668

669

670

671

672

673

674

675

676

677

678

679

680

681

682

683

684

685

686

687

688

Regime Shifts: A Whole-Ecosystem Experiment. Science 332(6033):1079-1082. doi: 10.1126/science. 1203672

Childress, W.M., Fitzpatrick, L.C., and Pearson, W.D. 1981. Trophic structure and energy flow in a Texas pond. Hydrobiologia 76(1):135-143. doi:10.1007/BF00014044

Clifford, H.F. 1972. A years' study of the drifting organisms in a brown-water stream of Alberta, Canada. Can. J. Zool. 50(7):975-983. doi:10.1139/z72-130

Cole, J.J., Caraco, N.F., and Likens, G.E. 1990. Short-range atmospheric transport: a significant source of phosphorus to an oligotrophic lake. Limnol. Oceanogr. 35(6):1230-1237. doi:10.4319/1o.1990.35.6.1230

Cole, J.J., Carpenter, S.R., Pace, M.L., Van de Bogert, M.C., Kitchell, J.L., and Hodgson, J.R. 2006. Differential support of lake food webs by three types of terrestrial organic carbon. Ecol. Lett. 9(5):558-568. doi:10.1111/j.1461-0248.2006.00898.x

Cusimano, C.A., Massa, B., and Morganti, M. 2016. Importance of meteorological variables for aeroplankton dispersal in an urban environment. Ital. J. Zool. 83(2):263-269. doi:10.1080/11250003.2016.1171915

Coulson, S.J., Hodkinson, I.D., Webb, N.R., and Harrison, J.A. 2002. Survival of terrestrial soil-dwelling arthropods on and in seawater: implications for trans-oceanic dispersal. Funct. Ecol. 16(3):353-356. doi:10.1046/j.1365-2435.2002.00636.x

del Giorgio, P.A., Cole, J.J., and Cimbleris, A. 1997. Respiration rates in bacteria exceed phytoplankton production in unproductive aquatic systems. Nature 385(6612):148-151. doi:10.1038/385148a0

Eby, L.A., Roach, W.J., Crowder, L.B., and Stanford, J.A. 2006. Effects of stocking-up freshwater food webs. Trends Ecol. Evol. 21(10):576-584. doi:10.1016/j.tree.2006.06.016 
689 Epanchin, P.N., Knapp, R.A., and Lawler, S.P. 2010. Nonnative trout impact an alpine690 nesting bird by altering aquatic-insect subsidies. Ecology 91(8):2406-2415. doi:10.3410/f.11944959.13068058

692

693

Finlay, J.C., and Vredenburg, V.T. 2007. Introduced trout sever trophic connections in watersheds: consequences for a declining amphibian. Ecology 88(9):2187-2198. doi:10.1890/06-0344.1

Forrester, G.E., Chace, J.G., and McCarthy, W. 1994. Diel and density-related changes in food consumption and prey selection by brook char in a New Hampshire stream. Env. Biol. Fish. 39(3):301-311. doi:10.1007/BF00005131

Hadfield, J.D. 2010. MCMC methods for multiresponse generalized linear mixed models: the MCMCglmm R package. J. Stat. Softw. 33(2):1-22. doi:10.18637/jss.v033.i02

Hadfield, J.D. 2015. MCMCglmm course notes. Available from http://cran.us.rproject.org/web/packages/ MCMCglmm/vignettes/CourseNotes.pdf [Accessed 1 October 2017]

Joseph, M.B., Piovia-Scott, J., Lawler, S.P., and Pope, K.L. 2011. Indirect effects of introduced trout on Cascades frogs (Rana cascadae) via shared aquatic prey. Freshwat. Biol. 56(5):828-838. doi:10.1111/j.1365-2427.2010.02529.x

Knapp, R.A., and Matthews, K.R. 1998. Eradication of nonnative fish by gill netting from a small mountain lake in California. Restor. Ecol. 6(2):207-213. doi:10.1111/j.1526100X.1998.06212.x

Knapp, R.A., Matthews, K.R., and Sarnelle, O. 2001. Resistance and resilience of alpine lake fauna to fish introductions. Ecol. Monogr. 71(3):401-421. doi:10.1890/00129615(2001)071[0401:RAROAL]2.0.CO;2 
712 Mason, C.F., and MacDonald, S.M. 1982. The input of terrestrial invertebrates from tree

713 canopies to a stream. Freshwat. Biol. 12(4):305-311. doi:10.1111/j.13652427.1982.tb00624.x

715

716

717

718

719

720

721

722

723

724

725

726

727

728

729

730

731

732

733

734

735
Mehner, T., Ihlau, J., Dörner, H., and Hölker, F. 2005. Can feeding of fish on terrestrial insects subsidize the nutrient pool of lakes? Limnol. Oceanogr. 50(6):2022-2031. doi:10.4319/lo.2005.50.6.2022

Mehner, T., Ihlau, J., Dörner, H., Hupfer, M., and Hölker, F. 2007. The role of insectivorous fish in fostering the allochthonous subsidy of lakes. Limnol. Oceanogr. 52(6):27182721. doi:10.4319/1o.2007.52.6.2718

Milardi, M., Käkelä, R., Weckström, J., and Kahilainen, K.K. 2015. Terrestrial prey fuels the fish population of a small, high-latitude lake. Aquat. Sci. 78(4):695-706. doi:10.1007/s00027-015-0460-1

Milardi, M., Lappalainen, J., McGowan, S., and Weckstrom, J. 2017. Can fish introductions alter nutrient cycles in previously fishless high-latitude lakes? J. Limnol. 76(1):1-14. doi:10.4081/jlimnol.2016.1364

Miró, A., and Ventura, M. 2013. Historical use, fishing management and lake characteristics explain the presence of non-native trout in Pyrenean lakes: implications for conservation. Biol. Conserv. 167:17-24. doi:10.1016/j.biocon.2013.07.016

Miró, A., and Ventura, M. 2015. Evidence of exotic trout mediated minnow invasion in Pyrenean high mountain lakes. Biol. Invasions 17(2):791-803. doi:10.1007/s10530014-0769-z

Nakagawa, S., and Schielzeth, H. 2013 A general and simple method for obtaining $\mathrm{R}^{2}$ from Generalized Linear Mixed-effects Models. Method Ecol. Evol. 4(2):133-142. doi:10.1111/j.2041-210x.2012.00261.x 
736 Nakano, S., and Murakami, M. 2001. Reciprocal subsidies: dynamic interdependence 737 between terrestrial and aquatic food webs. Proc. Natl Acad. Sci. 98(1):166-179. doi:10.1073/pnas.98.1.166

739

740

741

742

743

744

745

746

747

748

749

750

751

752

753

754

755

756

757

758

Nowlin, W.H., González, M.J., Vanni, M.J., Stevens, M.H.H., Fields, M.W., and Valente, J.J. 2007. Allochthonous subsidy of periodical cicadas affects the dynamics and stability of pond communities. Ecology 88(9):2174-2186. doi:10.1890/06-0570.1

Norlin, Å. 1964. The occurrence of terrestrial insects on the surface of two lakes in northern Sweden (Ankarvattnet and Blåsjön). Reports of the Institute of Freshwater Research of Drottningholm 45:196-205.

Norlin, Å. 1967. Terrestrial insects on lake surfaces, their availability and importance as fish food. Reports of the Institute of Freshwater Research of Drottningholm 47:39-55.

Pace, M., Cole, J.J., Carpenter, S.R., Kitchell, J.F., Hodgson, J.R., Van de Bogert, M.C., Bade, D.L., Kritzberg, E.S., and Bastviken, D. 2004. Whole-lake carbon-13 additions reveal terrestrial support of aquatic food webs. Nature 427(6971):240-243. doi:10.1038/nature02227

Panfili, J., De Pontual, H., Troadec, H., and Wrigh, P.J. 2002. Manual of fish sclerochronology. Ifremer-IRD, Brest, France.

Persson, A., and Svensson, J.M. 2006. Effects of benthivorous fish on biogeochemical processes in lake sediments. Freshwat. Biol. 51(7):1298-1309. doi:10.1111/j.13652427.2006.01569.x

Piovia-Scott, J., Sadro, S., Knapp, R.A., Sickman, J., Pope, K.L., and Chandra, S. 2016. Variation in reciprocal subsidies between lakes and land: perspectives from the mountains of California. Can. J. Fish. Aquat, Sci. 73(11):1691-1701. 
759 Psenner, R. 1984. The proportion of empneuston and total atmospheric inputs of carbon, 760 nitrogen and phosphorus in the nutrient budget of a small mesotrophic lake (Piburger 761 See, Austria). Internat. Rev. Hydrobiol. 69(1):23-39. doi:10.1002/iroh.19840690103

762 R Development Core Team, 2013. R: A Language and Environment for Statistical

763 Computing. R Foundation for Statistical Computing. Vienna, Austria. Available from 764 http://www.R-project.org/ [Accessed 1 November 2016]

765 Sabo, J.L., Bastow, J.L., and Power, M.E. 2002. Length-mass relationships for adult aquatic 766 and terrestrial invertebrates in a California watershed. J. North Am. Benthol.

767 Soc. 21(2):336-343.

768 Schindler, D.E., Knapp, R.A., and Leavitt, P.R. 2001. Alteration of nutrient cycles and algal

769

770

771

772

773

774

775

776 production resulting from fish introductions into mountain lakes. Ecosystems 4(4):308321. doi:10.1007/s10021-001-0013-4

Studier, E.H., and Sevick, S.H. 1992. Live mass, water content, nitrogen and mineral levels in some insects from south-central lower Michigan. Comp. Biochem. Physiol. A: Physiol. 103(3):579-595. doi:10.1016/0300-9629(92)90293-Y

Sweka, J.A., Cox, M.K., and Hartman, K.J. 2004. Gastric evacuation rates of brook trout. Trans. Am. Fish. Soc. 133(1):204-210. doi:10.1577/T02-064

Tiberti, R., Tartari, G., and Marchetto, A. 2010. Geomorphology and hydrochemistry of 12 Alpine lakes in the Gran Paradiso National Park, Italy. J. Limnol. 69(2):242-256. doi:10.4081/jlimnol.2010.242

Tiberti, R., von Hardenberg, A., and Bogliani, G. 2014a. Ecological impact of introduced fish in high altitude lakes: a case of study from the European Alps. Hydrobiologia 724(1):119. doi:10.1007/s10750-013-1696-1 
782 Tiberti, R., Rogora, M., Tartari, G., and Callieri, C. 2014b. Ecological impact of 783 transhumance on the trophic state of alpine lakes in Gran Paradiso National Park. Knowl. 784 Manag. Aquat. Ecosyst. 415:05. doi:10.1051/kmae $/ 2014030$

785 Tiberti, R., Brighenti, S., Canedoli, C., Iacobuzio, R., Pasquini, G., and Rolla, M. 2016. The 786 diet of introduced brook trout (Salvelinus fontinalis; Mitchill, 1814) in an alpine area 787 and a literature review on its feeding ecology. J. Limnol. 75(3):488-507. $788 \quad$ doi:10.4081/jlimnol.2016.1366

789 Tiberti, R., Ottino, M., Brighenti, S., Iacobuzio, R., Rolla, M., von Hardenberg, A., and 790 Bassano, B. 2017. Involvement of recreational anglers in the eradication of alien brook 791 trout from alpine lakes. J. Mount. Ecol., in press.

792 Vander Zanden, M.J., and Gratton, C. 2011. Blowin' in the wind: reciprocal airborne carbon 793 fluxes between lakes and land. Can. J. Fish. Aquat. Sci. 68(1):170-182.

794 doi:10.1139/F10-157

795 Vanni, M.J. 2002. Nutrient cycling by animals in freshwater ecosystems. Annu. Rev. Ecol. 796 Syst. 33(1):341-370. doi:10.1146/annurev.ecolsys.33.010802.150519

797 Ventura, M., Tiberti, R., Buchaca, T., Buñay, D., Sabás, I., and Miró, A. 2017. Why should 798 we preserve fishless high-mountain lakes? Springer books. In Press

799 Wurtsbaugh, W.A. 2007. Nutrient cycling and transport by fish and terrestrial insect nutrient $800 \quad$ subsidies to lakes. Limnol. Oceanograph. 52(6):2715-2718.

801 doi:10.4319/lo.2007.52.6.2715 
802 Tables

803 Table 1 Main geographic, morphometric and chemical data of GPNP studied lakes; $\mathrm{D}_{\max }$ :

804 maximum depth; A: area; Geology - AG: catchment entirely composed by acidic gneiss;

805 Geology - CS: catchment dominated by thick covering of calcareous schists. Chemical

806 variables are expressed as mean $\pm \mathrm{SD}$ from 14-28 repeated sampling (between 2008 and

807 2015). TP: total phosphorus; Fish-N: naturally fishless lakes; Fish-Y: stocked lakes; Fish-E:

808 lakes under fish eradication.

\begin{tabular}{|c|c|c|c|c|c|c|c|c|c|c|}
\hline & LOS & NIS & TRS & LEI & ROS & NII & DJO & DRE & NER & LEY \\
\hline Latitude N & $45^{\circ} 28^{\prime} 32^{\prime \prime}$ & $45^{\circ} 28^{\prime} 41^{\prime \prime}$ & $45^{\circ} 30^{\prime} 07^{\prime \prime}$ & $45^{\circ} 29^{\prime} 37^{\prime \prime}$ & $45^{\circ} 28^{\prime} 49^{\prime \prime}$ & $45^{\circ} 29^{\prime} 10^{\prime \prime}$ & $45^{\circ} 33^{\prime} 27^{\prime \prime}$ & $45^{\circ} 24^{\prime} 45^{\prime \prime}$ & $45^{\circ} 33^{\prime} 06^{\prime \prime}$ & $45^{\circ} 30^{\prime} 28^{\prime \prime}$ \\
\hline Long & $07^{\circ} 09^{\prime} 25^{\prime \prime}$ & $07^{\circ} 08^{\prime} 55^{\prime \prime}$ & $07^{\circ} 08^{\prime} 40^{\prime \prime}$ & $07^{\circ} 07^{\prime} 55^{\prime \prime}$ & $07^{\circ} 08^{\prime} 17^{\prime \prime}$ & $07^{\circ} 08^{\prime} 45^{\prime \prime}$ & $07^{\circ} 10^{\prime} 43^{\prime \prime}$ & $07^{\circ} 13^{\prime} 25^{\prime \prime}$ & $07^{\circ} 10^{\prime} 07^{\prime \prime}$ & $07^{\circ} 09^{\prime} 08^{\prime \prime}$ \\
\hline Altitu & 2568 & 2538 & 2729 & 2701 & 2703 & & & & 2671 & 27 \\
\hline $\mathrm{D}_{\max }(\mathrm{m})$ & 7.2 & 17.1 & 7 & 11.0 & 46.9 & 1 & 3. & 7 & 6. & 22.1 \\
\hline & 2 & 3.4 & 1 & 6.2 & 16.9 & 8. & 1. & 2. & & 4.5 \\
\hline Geol & $\mathrm{AG}$ & $\mathrm{AG}$ & CS & CS & $\mathrm{CS}$ & CS & CS & $\mathrm{AC}$ & CS & CS \\
\hline $\mathrm{pH}$ & $7.0 \pm 0.2$ & $7.1 \pm 0.3$ & $8.0 \pm 0.3$ & $8.1 \pm 0.2$ & $7.8 \pm 0.2$ & $7.7 \pm 0.4$ & $8.7 \pm 0.4$ & $7.0 \pm 0.5$ & $8.0 \pm 0.3$ & $8.0 \pm 0.3$ \\
\hline $\mathrm{TP}\left(\mu \mathrm{g} \mathrm{L}^{-1}\right)$ & $4.0 \pm 2.1$ & $5.7 \pm 3.6$ & $3.2 \pm 1.9$ & $1.8 \pm 0.8$ & $3.9 \pm 1.0$ & $8.1 \pm 3.0$ & $3.5 \pm 1.3$ & $4.3 \pm 2.5$ & $2.3 \pm 1.6$ & $3.0 \pm 0.9$ \\
\hline Fish & $\mathrm{N}$ & $\mathrm{N}$ & $\mathrm{N}$ & $\mathrm{Y}$ & Y & Y & E & E & E & E \\
\hline
\end{tabular}


810 Table 2 Sampling of sinking arthropods and estimated number and biomass (in $\mathrm{mg}$ ) of

811 sinking arthropods in 10 high altitude lakes contrasting for their stocking history (Fish-N:

812 fishless: Fish-Y: stocked; Fish-E: lakes treated for fish eradication). Sampling effort (start

813 and end dates of sampling, number of elapsed days) and the number of active traps (in

814 brackets) are provided for each sampling session. Sampling took place in 2013 in the Gran

815 Paradiso National Park, Western Italian Alps.

\begin{tabular}{|c|c|c|c|c|c|}
\hline \multirow{2}{*}{\multicolumn{2}{|c|}{ Lake Fish Sampling sessions }} & \multirow{2}{*}{\multicolumn{2}{|c|}{$\begin{array}{l}\text { Number of sinking arthropods } \pm 95 \% \mathrm{CI} \\
\text { trap }^{-1} \times \text { day }^{-1} \\
\end{array}$}} & \multicolumn{2}{|c|}{ Biomass of sinking arthropods $\pm 95 \% \mathrm{CI}$} \\
\hline & & & & $\mathrm{mg} \times \operatorname{trap}^{-1} \times$ day $^{-1}$ & $\mathrm{mg} \times \mathrm{m}^{-2} \times$ day $^{-1}$ \\
\hline LOS N & $\begin{array}{l}26 / 07-31 / 07,5(6) \\
01 / 08-06 / 08,5(8) \\
09 / 08-14 / 08,5(8)\end{array}$ & $0.35 \pm 0.25$ & $1.40 \pm 0.49$ & $1.06 \pm 0.43$ & $4.29 \pm 0.87$ \\
\hline NIS $\mathrm{N}$ & $\begin{array}{l}15 / 08-20 / 08,5(8) \\
20 / 08-25 / 08,5(8) \\
25 / 08-30 / 08,5(8)\end{array}$ & $0.06 \pm 0.10$ & $0.24 \pm 0.19$ & $0.06 \pm 0.10$ & $0.24 \pm 0.19$ \\
\hline TRS N & $\begin{array}{l}26 / 08-31 / 08,5(8) \\
31 / 08-07 / 09,7(8) \\
07 / 09-12 / 09,5(8)\end{array}$ & $0.01 \pm 0.03$ & $0.02 \pm 0.06$ & $0.00 \pm 0.01$ & $0.00 \pm 0.03$ \\
\hline LEI Y & $\begin{array}{l}27 / 08-01 / 09,5(8) \\
01 / 09-08 / 09,7(8) \\
09 / 09-13 / 09,4(8)\end{array}$ & $0.09 \pm 0.11$ & $0.36 \pm 0.24$ & $0.38 \pm 0.25$ & $1.53 \pm 0.50$ \\
\hline ROS Y & $\begin{array}{l}05 / 08-10 / 08,5(8) \\
10 / 08-16 / 08,6(8) \\
16 / 08-21 / 08,5(4) \\
21 / 08-26 / 08,5(8)\end{array}$ & $0.04 \pm 0.08$ & $0.17 \pm 0.15$ & $0.04 \pm 0.08$ & $0.18 \pm 0.16$ \\
\hline NII Y & $\begin{array}{l}30 / 08-06 / 09,7(8) \\
07 / 09-11 / 09,4(8) \\
11 / 09-15 / 09,4(8)\end{array}$ & $0.02 \pm 0.06$ & $0.08 \pm 0.12$ & $0.05 \pm 0.09$ & $0.18 \pm 0.17$ \\
\hline DJO E & $\begin{array}{l}06 / 07-11 / 07,5(8) \\
12 / 07-19 / 07,7(8)\end{array}$ & $0.26 \pm 0.25$ & $1.04 \pm 0.50$ & $1.03 \pm 0.50$ & $4.20 \pm 1.00$ \\
\hline DRE E & $\begin{array}{l}25 / 06-30 / 06,5(8) \\
02 / 07-07 / 07,5(8) \\
07 / 07-15 / 07,8(8)\end{array}$ & $0.04 \pm 0.08$ & $0.17 \pm 0.16$ & $0.11 \pm 0.13$ & $0.43 \pm 0.26$ \\
\hline NER E & $\begin{array}{l}11 / 07-16 / 07,5(8) \\
20 / 07-25 / 07,5(8)\end{array}$ & $0.11 \pm 0.16$ & $0.46 \pm 0.33$ & $0.13 \pm 0.18$ & $0.53 \pm 0.36$ \\
\hline LEY E & $\begin{array}{l}01 / 08-13 / 08,12(8) \\
13 / 08-18 / 08,5(8) \\
18 / 08-25 / 08,7(8)\end{array}$ & $0.02 \pm 0.05$ & $0.07 \pm 0.11$ & $0.03 \pm 0.07$ & $0.12 \pm 0.14$ \\
\hline
\end{tabular}

816

817 
818 Table 3. Posterior density mean estimates \pm 95\% Credibility Intervals (from Bayesian

819 generalized mixed model with Markov-chain Monte-Carlo estimate) of the number of sinking

820 arthropods (response variables) in high mountain lakes contrasting fort their stocking history

821 (Treatment - Y: lake with fish; Treatment - N: lake without fish; Treatment - E: lake treated

822 for fish eradication), sampled at different depths (Depth - surface $=0.05 \mathrm{~m}$; Depth - bottom $=$

$8231.5 \mathrm{~m}$ ), and for a variable number of days (Day). Samples were collected in 2013 from 113

824 surface vs. benthic pairs of traps in 10 lakes of the Gran Paradiso National Park (Italy).

825 Significant p-values (pMCMC) are presented in bold.

826

\begin{tabular}{llrcr}
\hline Factor & & Post-mean & 95\%CI & pMCMC \\
\hline Day & & 0.13 & $0.05-0.25$ & $<\mathbf{0 . 0 5}$ \\
Depth & (bottom vs. surface) & 0.28 & $-0.27-0.77$ & 0.1 \\
Treatment & E vs. N & -1.67 & $-5.04-0.86$ & 0.2 \\
& E vs. Y & -0.33 & $-3.88-2.11$ & 0.8 \\
& N vs. Y & 0.48 & -3.224 .93 & 0.8 \\
Treatment:Depth & E vs. N & 0.66 & $0.21-1.56$ & $<\mathbf{0 . 0 5}$ \\
& E vs. Y & -0.21 & $-1.94-0.41$ & 0.9 \\
& N vs. Y & -0.41 & $-1.17-0.43$ & 0.8 \\
\hline
\end{tabular}

827 
828 Table 4 Number of lake-dwelling brook trout belonging to different size classes removed at

829 the end of an eradication campaign in four alpine lakes of the Gran Paradiso National Park.

8301693 and 9 additional brook trout were removed by electrofishing from the tributaries of

831 Lakes DRE and DJO.

\begin{tabular}{lrrrrr} 
& Lake & DJO & DRE & LEY & NER \\
\hline Lake dwelling brook trout & & & & & \\
Class $1(<15 \mathrm{~cm})$ & & 447 & 10739 & 898 & 18 \\
Class 2 $(\geq 15 \mathrm{~cm}$ and $<20 \mathrm{~cm})$ & & 113 & 738 & 434 & 1 \\
Class 3 $(\geq 20 \mathrm{~cm}$ and $<25 \mathrm{~cm})$ & & 683 & 1213 & 1781 & 14 \\
Class 4 $(\geq 25 \mathrm{~cm})$ & 159 & 802 & 69 & 167 \\
Not available & 3 & 36 & 261 & 1 \\
& & $\mathbf{1 3 9 6}$ & $\mathbf{1 3 5 2 8}$ & $\mathbf{3 4 4 4}$ & $\mathbf{2 0 1}$ \\
\hline & TOTAL & $\mathbf{0 . 1 0 8}$ & $\mathbf{0 . 5 8 5}$ & $\mathbf{0 . 0 7 7}$ & $\mathbf{0 . 0 1 2}$ \\
\hline
\end{tabular}

832 
833 Table 5 Diet of Salvelinus fontinalis belonging to size classes 1-4 (from $<15 \mathrm{~cm}$ to $\geq 25 \mathrm{~cm}$

834

835

836

837 at $5 \mathrm{~cm}$ intervals) from alpine lakes in Gran Paradiso National Park. N: number of analyzed stomachs; $\overline{\mathrm{N}}$ : mean prey number per stomach; F\%: frequency of occurrence of the prey groups; $\mathrm{A} \%$ : percent relative abundance of the prey groups; $\overline{\mathrm{V}}$ : mean biovolume per stomach.

\begin{tabular}{|c|c|c|c|c|c|c|c|c|c|c|c|c|c|c|c|c|c|}
\hline & \multicolumn{5}{|c|}{ Class 1} & \multicolumn{4}{|c|}{ Class 2} & \multicolumn{4}{|c|}{ Class 3} & \multicolumn{4}{|c|}{ Class 4} \\
\hline & & $\overline{\mathbf{N}}$ & $\begin{array}{l}\mathbf{F} \\
\%\end{array}$ & $\mathbf{A} \%$ & $\underset{\mathrm{mL}}{\overline{\mathbf{V}}}$ & $\overline{\mathbf{N}}$ & $\begin{array}{l}\mathbf{F} \\
\%\end{array}$ & $\begin{array}{l}\mathbf{A} \\
\%\end{array}$ & $\underset{\mathrm{mL}}{\overline{\mathbf{V}}}$ & $\overline{\mathbf{N}}$ & $\begin{array}{l}\mathbf{F} \\
\%\end{array}$ & $\begin{array}{l}\mathbf{A} \\
\%\end{array}$ & $\underset{\mathrm{mL}}{\overline{\mathbf{V}}}$ & $\overline{\mathbf{N}}$ & $\begin{array}{l}\mathbf{F} \\
\%\end{array}$ & $\begin{array}{l}\mathbf{A} \\
\%\end{array}$ & $\underset{\mathrm{mL}}{\overline{\mathbf{V}}}$ \\
\hline & $\mathbf{N}=$ & 122 & 122 & 122 & 22 & 44 & 44 & 44 & 54 & 68 & 68 & 68 & 75 & 72 & 72 & 72 & 85 \\
\hline \multicolumn{18}{|l|}{$\begin{array}{l}\text { Prey groups } \\
\end{array}$} \\
\hline 1. AQUATIC MICl & & 26.9 & 45.1 & 34.8 & 0.0 & - & - & - & - & 40.7 & 7.4 & 14.6 & 0.04 & 43.5 & 1.4 & 34.4 & 0.0 \\
\hline 2. AQUATIC INVERTEBRATE & & 49.4 & 88.5 & 63.8 & 0.1 & 86.5 & 88.6 & 95.7 & 0.3 & 216.7 & 83.8 & 77.7 & 0.5 & 26.3 & 68.1 & 20.8 & 0.2 \\
\hline 3. $\mathrm{Tl}$ & & 6.1 & 53.3 & 7.92 & 0.1 & 3.9 & 59.1 & 4.2 & 0.1 & 21.7 & 82.4 & 7.8 & 0.5 & 56.6 & 87.5 & 44.7 & 1.7 \\
\hline $3.1 \mathrm{G}$ & & 1.0 & 27.8 & 1.3 & 0.1 & 2.0 & 47.7 & 2.2 & 0.1 & 7.9 & 72.1 & 2.8 & 0.3 & 25.2 & 84.7 & 19.9 & 0.9 \\
\hline Terrestrial Coleoptera & & 0.9 & 27.0 & 1.1 & 0.0 & 1.9 & 43.1 & 2.1 & 0.1 & 7.5 & 69.1 & 2.7 & 0.3 & 21.2 & 77.8 & 16.8 & 0.8 \\
\hline & & - & - & & - & - & & - & - & 0.0 & 1.4 & 0.0 & 0.0 & 0.0 & 2.8 & 0.0 & 0.0 \\
\hline Lepid & & - & - & - & - & - & - & - & - & 0.1 & 1.4 & 0.0 & 0.0 & - & & - & 0.0 \\
\hline Hemiptera & & 0.1 & 4.1 & 0.2 & 0.0 & 0.0 & 2.3 & 0.0 & 0.0 & 0.2 & 5.9 & 0.1 & 0.0 & 3.2 & 16.7 & 2.55 & 0.0 \\
\hline & & 0.0 & 0.8 & 0.0 & 0.0 & - & & - & - & - & - & - & - & - & - & - & \\
\hline Arane & & 0.0 & 0.8 & 0.0 & 0.0 & 0.0 & 2.3 & 0.0 & 0.0 & 0.0 & 1.4 & 0.0 & 0.0 & 0.1 & 5.6 & 0.0 & 0.0 \\
\hline Miria & & - & - & - & - & - & - & - & - & - & - & - & - & 0.0 & 1.4 & 0.0 & 0.0 \\
\hline $3.2 \mathrm{Gr}$ & & 0.0 & 2.4 & 0.0 & 0.0 & 0.0 & 2.3 & 0.0 & 0.0 & 0.2 & 11.8 & 0.1 & 0.0 & 0.4 & 13.9 & 0.32 & 0.0 \\
\hline & & 0.0 & 1.6 & 0.0 & 0.0 & 0.0 & 2.3 & 0.0 & 0.0 & 0.2 & 7.4 & 0.1 & 0.0 & 0.3 & 6.9 & 0.3 & 0.0 \\
\hline Tricoptera, i & & 0.0 & 0.8 & 0.0 & 0.0 & - & - & - & - & 0.1 & 4.4 & 0.0 & 0.0 & 0.1 & 6.9 & 0.1 & 0.0 \\
\hline 3.3 Grou & & 5.1 & 44.3 & 6.5 & 0.1 & 1.9 & 34.1 & 2.1 & 0.0 & 13.6 & 61.8 & 4.9 & 0.2 & 31.0 & 77.8 & 24.5 & 0.8 \\
\hline 4. VERTEBRATES & & & & & & & & & - & 0.0 & 2.9 & 0.0 & 0.0 & 0.1 & 9.7 & 0.1 & 0.9 \\
\hline
\end{tabular}




\section{$838 \quad$ Figure legends}

839 Fig. 1 Map of the Gran Paradiso National Park - GPNP (A), its location on the Alps (B), and 840 location of the study lakes. Triangles: "eradication lakes"; dark circles: lakes containing 841 brook trout (Salvelinus fontinalis); pale circles: naturally fishless lakes; small circles: additive 842 lakes for the sampling of brook trout diet analysis.

843 Fig. 2 A: Plan and side elevation view of a funnel trap consisting of an inverted cone made of 844 plastic net ( $1 \mathrm{~mm}$ mesh size) and ending in a bottle, dotted lines indicate alignment; B: paired benthic and surface funnel traps (traps plot; B) used to estimate the number of sinking arthropods and the proportion of terrestrial arthropods reaching the lake bottom.

Fig. 3 Water temperatures and insect categories used to test the underwater timing of

848 decomposition of terrestrial arthropods in Lake DRE.

849 Fig. 4 Comparison between number/biomass of sinking arthropods and daily CTA

850 (Consumption of Terrestrial Arthropods) and BCTA (daily Biomass of Consumed Terrestrial 851 Arthropods) ranges in four populations of brook trout inhabiting high altitude lakes. Solid 852 lines: mean $\pm 95 \%$ CI number/biomass of sinking arthropods; grey bars: CTA/ BCTA ranges.

853 Fig. 5 Example of arthropods subsidy mediated by a fish predator (black arrows) or not (grey 854 arrows). Input and output pathways for terrestrial arthropods include: arthropods falling from 855 the littoral area (Input1), drifting on the tributaries surface (Input2), or in their water column 856 (Input 3), aerial plankton falling into the lakes (Input4), alive arthropods leaving the lakes 857 from the surface (Output1) or when reaching the shore (Output2), dead arthropods washed out to the land (Output3), and drifting arthropods leaving the lakes from the outflowing rivers 859 (Output 4). Arthropods from Input3 and a fraction of those from 1,2, and 4 sinks to the lakes bottom (S1 and S2) or is consumed by fish (F2 and F3), together with some arthropods 861 drifting on the lakes surface (F1). Metabolic wastes include a fraction of particulate matter 862 which sink to the bottom (S3) and soluble excretes (E) which dissolve in the water column. 


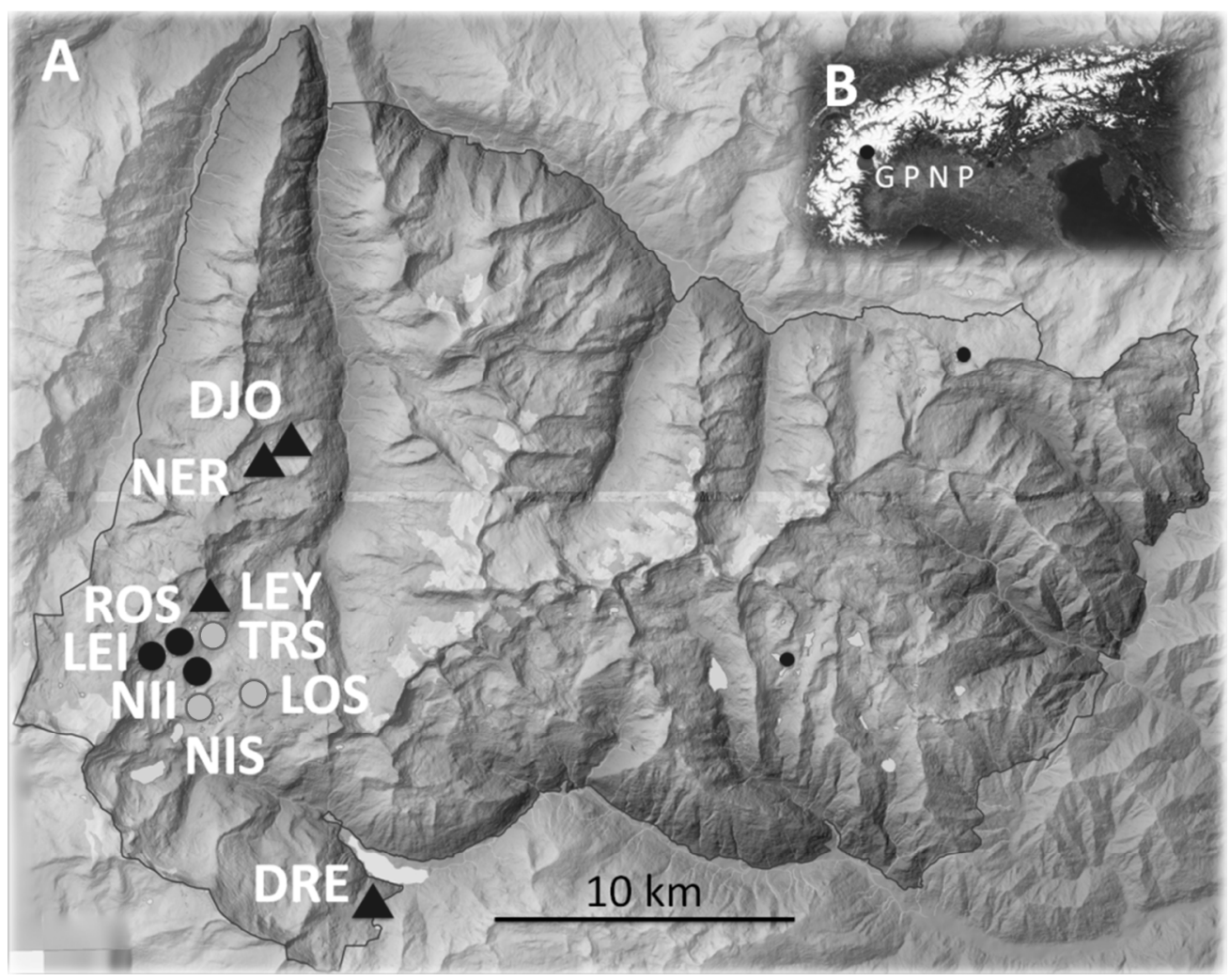

Map of the Gran Paradiso National Park - GPNP (A), its location on the Alps (B), and location of the study lakes. Triangles: "eradication lakes"; dark circles: lakes containing brook trout (Salvelinus fontinalis); pale circles: naturally fishless lakes; small circles: additive lakes for the sampling of brook trout diet analysis.

$300 \times 237 \mathrm{~mm}(300 \times 300 \mathrm{DPI})$ 


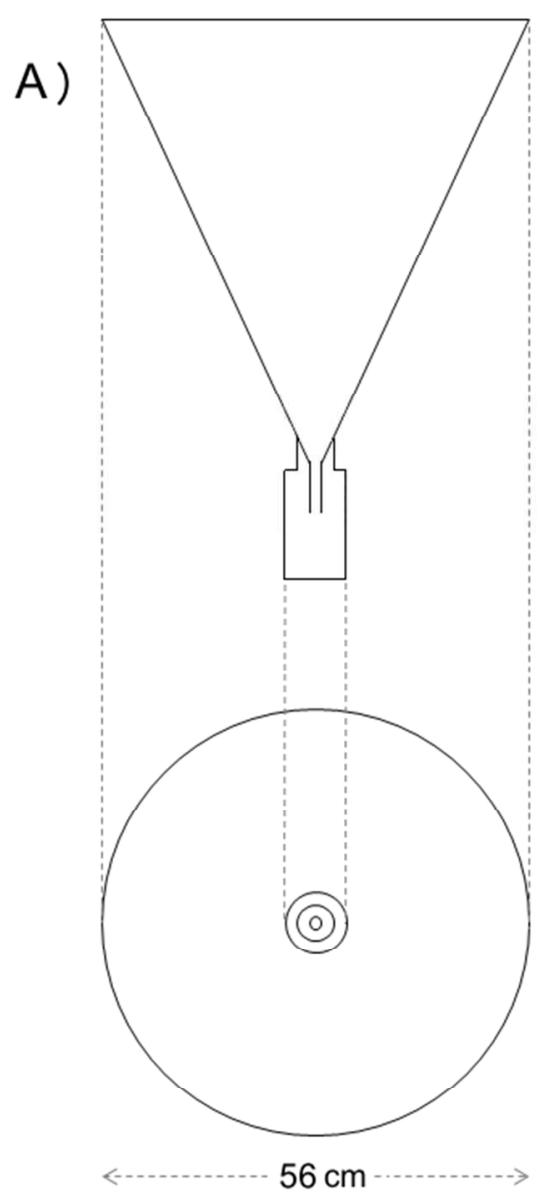

\section{B)}

WATER SURFACE

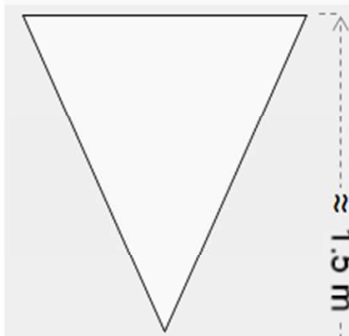

LAKE BOTTOM - $2 \mathrm{~m}$

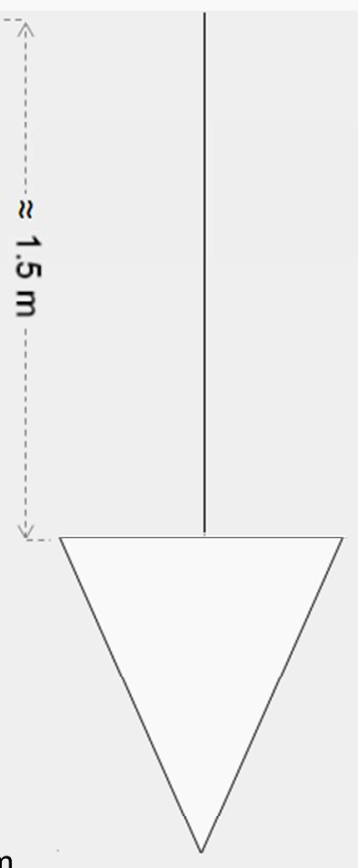

Fig. 2 A: Plan and side elevation view of a funnel trap consisting of an inverted cone made of plastic net (1 $\mathrm{mm}$ mesh size) and ending in a bottle, dotted lines indicate alignment; B: paired benthic and surface funnel traps (traps plot; B) used to estimate the number of sinking arthropods and the proportion of terrestrial arthropods reaching the lake bottom.

$254 \times 243 \mathrm{~mm}$ ( $300 \times 300$ DPI) 

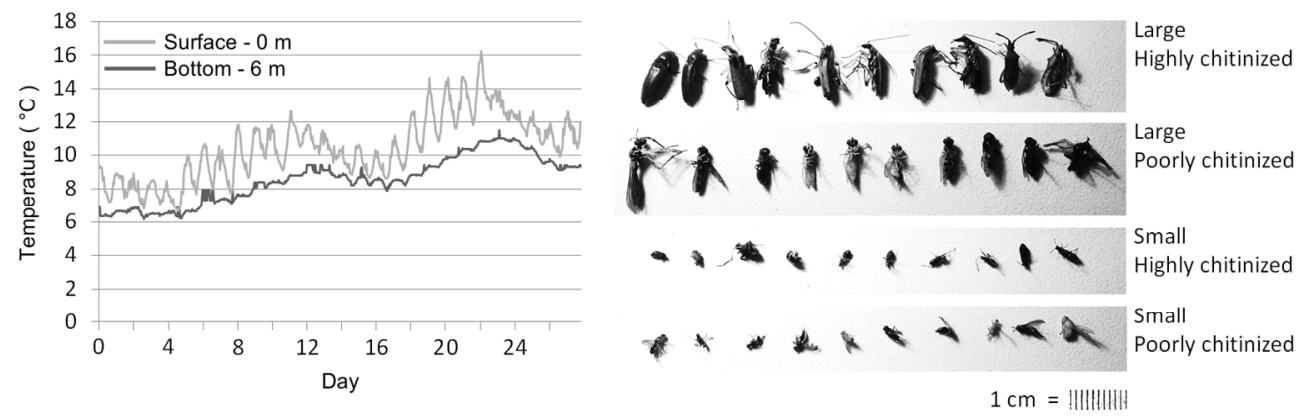

Water temperatures and insect categories used to test the underwater timing of decomposition of terrestrial arthropods in Lake DRE.

$146 \times 47 \mathrm{~mm}(300 \times 300 \mathrm{DPI})$ 

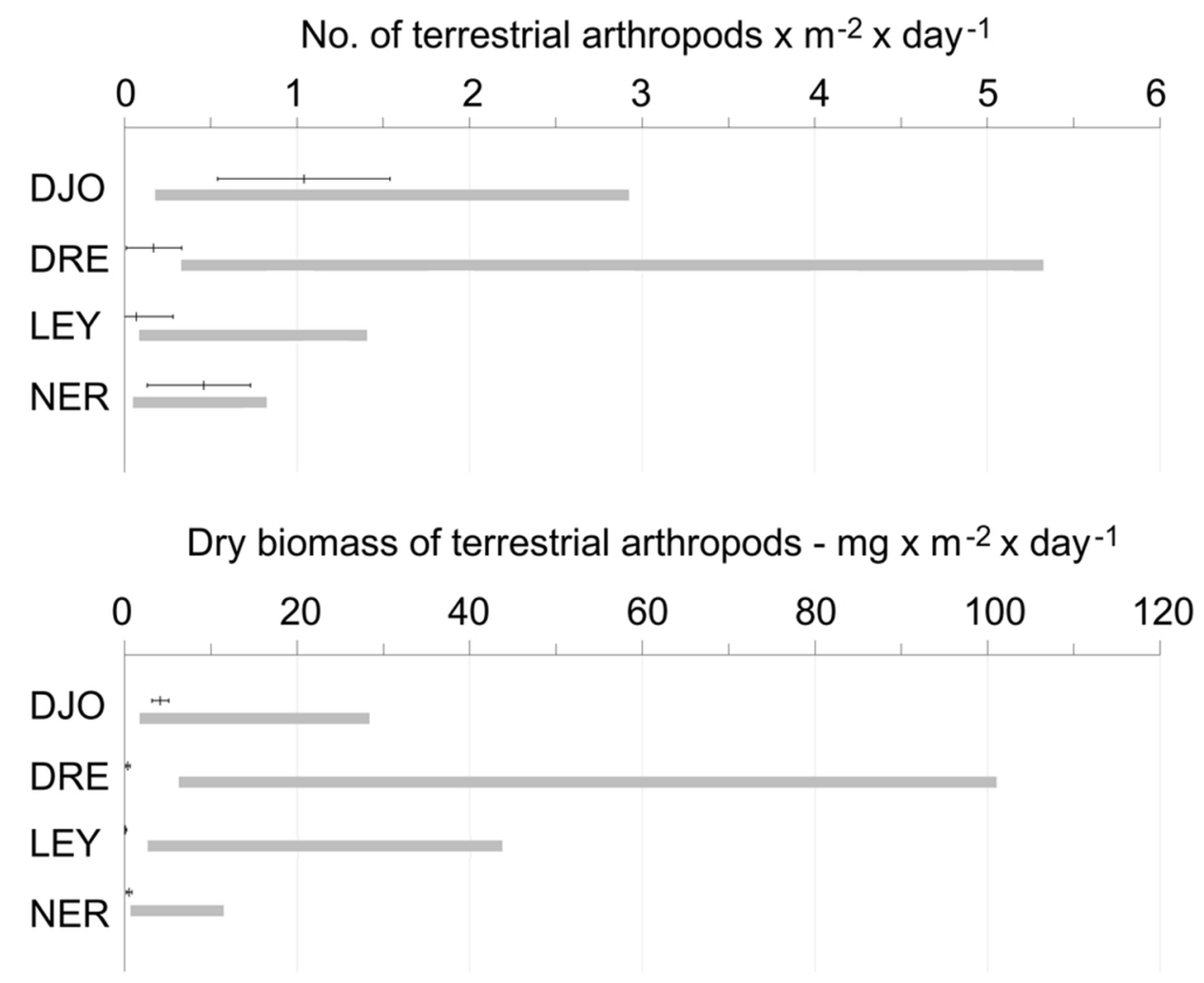

Fig. 4 Comparison between number/biomass of sinking arthropods and daily CTA (Consumption of Terrestrial Arthropods) and BCTA (daily Biomass of Consumed Terrestrial Arthropods) ranges in four populations of brook trout inhabiting high altitude lakes. Solid lines: mean $\pm 95 \% \mathrm{CI}$ number/biomass of sinking arthropods; grey bars: CTA/ BCTA ranges.

$89 \times 73 \mathrm{~mm}(300 \times 300$ DPI $)$ 


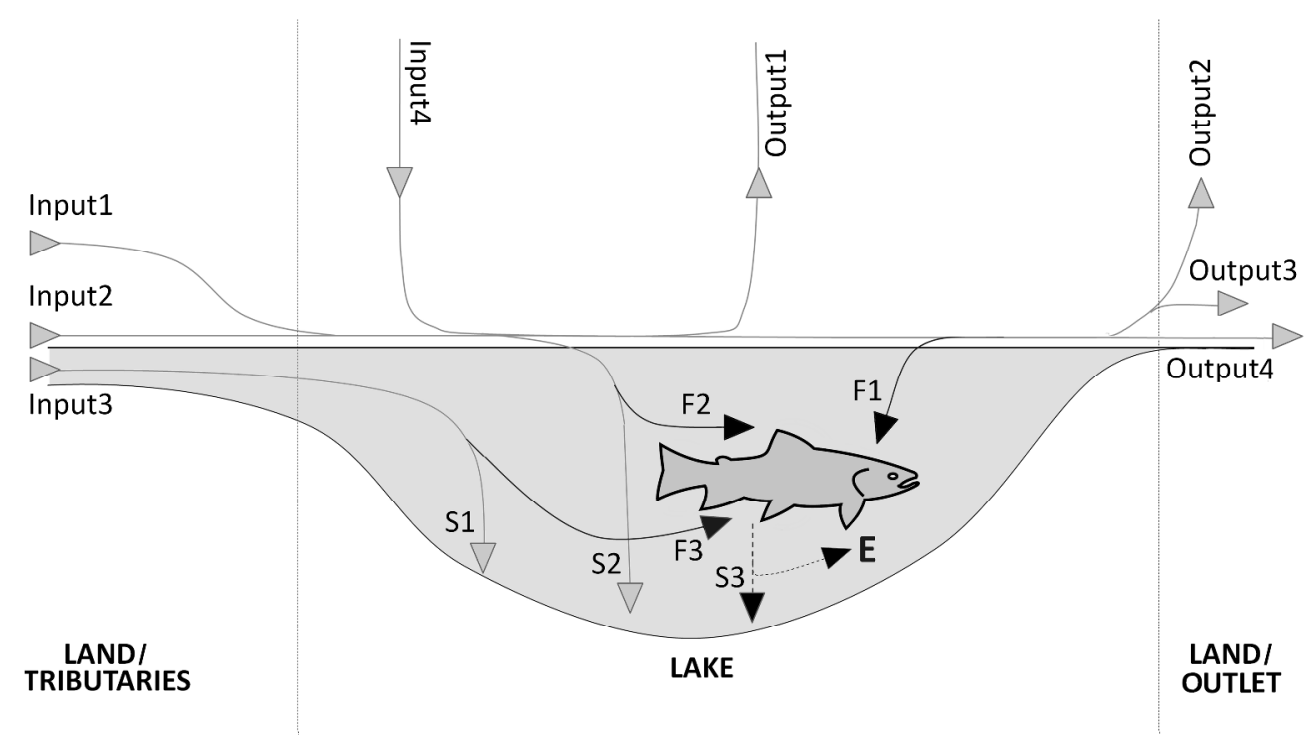

Fig. 5 Example of arthropods subsidy mediated by a fish predator (black arrows) or not (grey arrows). Input and output pathways for terrestrial arthropods include: arthropods falling from the littoral area (Input1), drifting on the tributaries surface (Input2), or in their water column (Input 3), aerial plankton falling into the lakes (Input4), alive arthropods leaving the lakes from the surface (Output1) or when reaching the shore (Output2), dead arthropods washed out to the land (Output3), and drifting arthropods leaving the lakes from the outflowing rivers (Output 4). Arthropods from Input3 and a fraction of those from 1,2, and 4 sinks to the lakes bottom (S1 and S2) or is consumed by fish (F2 and F3), together with some arthropods drifting on the lakes surface (F1). Metabolic wastes include a fraction of particulate matter which sink to the bottom (S3) and soluble excretes (E) which dissolve in the water column.

$438 \times 251 \mathrm{~mm}(300 \times 300$ DPI $)$ 